\title{
A CRIANÇA INTERIOR E O CASAMENTO: REFLEXÕES A PARTIR DO CURSO CUIDANDO DO CUIDADOR ${ }^{1}$
}

\author{
EL NIÑO INTERIOR Y EL MATRIMONIO: REFLEXIONES DEL CURSO DE \\ CUIDADO DEL CUIDADOR
}

\author{
THE INNER CHILD AND MARRIAGE: REFLECTIONS FROM THE COURSE \\ CARING FOR THE CAREGIVER
}

Maria da Graça Pedrazzi MARTINI²

\begin{abstract}
RESUMO: O objetivo desse estudo de caso, foi compreender o efeito da descoberta da criança interior no relacionamento conjugal dos participantes do Curso: TRA: Capacitação em Técnicas de Resgate da Autoestima - Cuidando do Cuidador. Trata-se de um estudo de caso de um casal avaliado por meio de entrevista, realizada após a vivência do resgate da criança interior no início do curso, gravações das partilhas das vivências e o registro de observações no caderno de notas da pesquisadora. Para analisar as opiniões coletadas, utilizou-se como metodologia a análise do discurso. Os resultados apontaram, uma maior consciência da interferência da criança interior no relacionamento conjugal e a necessidade de estar mais atento diante de suas manifestações para evitar futuros conflitos. Portanto, o curso Cuidando do Cuidador ofereceu um espaço de aprendizagem do acolhimento da criança interior e de autocuidado, bem como uma forma de aprender a cuidar do outro.
\end{abstract}

PALAVRAS-CHAVE: Criança interior. Relacionamento conjugal. Autoconhecimento.

RESUMEN: El objetivo de este estudio de caso fue comprender el efecto del descubrimiento del niño interior en la relación conyugal de los participantes del Curso: TRA: Formación en Técnicas de Rescate de la Autoestima - Cuidando al Cuidador. Se trata de un estudio de caso de una pareja evaluada a través de una entrevista, realizada luego de la experiencia de rescatar al niño interior al inicio del curso, grabaciones del intercambio de experiencias y el registro de observaciones en el cuaderno del investigador. Para analizar las opiniones recogidas se utilizó como metodología el análisis del discurso. Los resultados mostraron una mayor conciencia de la interferencia del niño interior en la relación conyugal y la necesidad de estar más atento a sus manifestaciones para evitar conflictos futuros. Por ello, el curso Cuidando al cuidador ofreció un espacio para aprender a acoger al niño interior y al autocuidado, así como una forma de aprender a cuidar de los demás.

\footnotetext{
${ }^{1}$ Os dados deste artigo foram coletados durante a pesquisa pra elaboração da Tese de Doutorado em Terapia Familiar, da autora, orientada por Ana Lúcia de Moraes Horta, intitulada: Efeito do Curso Cuidando do Cuidador e a Relação com a Criança Interior, pelo CAIFCOM - Instituto de Cuidado, Atendimento, Ensino e Pesquisa do Indivíduo, Família e Comunidade e Faculdade Evangélica do Meio Norte, Porto Alegre, defendida em 08 novembro de 2015.

${ }^{2}$ Secretaria Municipal de Educação, Londrina - PR - Brasil. Psicopedagoga Aposentada. Doutorado em Terapia Familiar e Casal (CAIFCOM). Diretora e formadora do Movimento Terapêutico: Espaço de Desenvolvimento Humano Graça Martini - Polo Formador em TCI. ORCID: https://orcid.org/0000-0001-8055-4561. E-mail: gracapedrazzi@gmail.com
} 
PALABRAS CLAVE: Niño interior. Relacion matrimonial. Conocimiento de sí mismo.

ABSTRACT: The objective of this case study, was to understand the effect of the discovery of the inner child in the conjugal relationship of the participants of the Course: TRA: Capacitation in Techniques of Self-Esteem Rescue - Caring for the Caregiver. This is a case study of a couple evaluated through an interview, carried out after the experience of the inner child rescue at the beginning of the course, recordings of the experience sharing and the register of observations in the researcher's notebook. To analyze the opinions collected, the methodology used was discourse analysis. The results showed a greater awareness of the interference of the inner child in the conjugal relationship and the need to be more attentive to its manifestations to avoid future conflicts. Therefore, the Care for the Caregiver course offered a learning space for the inner child and self-care, as well as a way to learn how to care for the other.

KEYWORDS: Inner child. Marital relationship. Self knowledge.

\section{Introdução}

Quando se fala em casamento, a ideia de uma cinderela e seu príncipe "felizes para sempre", logo vem à mente. Entretanto, a união conjugal constituída, inicialmente, por sonhos de uma vida feliz, marcada pela paixão, pelo amor romântico, ilusões dos contos de fadas e por fim, um grande desejo de cumprir os juramentos feitos no altar de estarem "juntos" na alegria e na tristeza, na saúde e na doença até que a morte os separe”, acaba em conflitos, sofrimentos sem fim, e por vezes, em divórcio. O que acontece entre o sonho otimista do altar e frustação da convivência?

A relevância do tema baseia-se nas evidências de que em algum momento do relacionamento, o casal irá experimentar as consequências da manifestação da criança interior.

A criança interior é a criança que fomos um dia. É a "mala, a bagagem" de experiências vividas na infância e que está dentro de nós. A criança interior nos acompanha durante toda a nossa vida e tende a influenciar nossas decisões e comportamentos. A criança interior nada mais é que o nosso Self, o verdadeiro "Eu”, o "Eu Sou”. Já a criança ferida é aquela que sofreu situações de violência, privações das necessidades básicas, abandono, rejeição, traumas etc. Estas marcas causam consequências na vida adulta. Por isso, é importante conversar com a essa criança interior e ajudá-la a compreender com um olhar adulto, a dor do passado, incentivá-la e apoiá-la a superar as situações difíceis que teve que enfrentar, para que assim, o adulto de hoje possa desapegar-se desses traumas guardados nos porões do inconsciente, aliviando o peso da "mala" de sentimentos e sofrimentos do passado. É muito terapêutico acolher todas as necessidades não satisfeitas da criança interior. 
A “criança vitoriosa" surge quando a criança interior se manifesta de forma saudável, trazendo a força e a energia vital contida em todo o ser humano, que se manifesta em forma de coragem, entusiasmo e equilíbrio. O desconhecimento dessa criança interior poderá potencializar o conflito e desencadear mais insatisfações.

O Curso Cuidando do Cuidador oferece este espaço de reflexão e acolhimento, promovendo o autoconhecimento, por meio de suas dez vivências terapêuticas. A primeira delas resgata a criança interior, e as demais vivências terapêuticas, trabalham seu sofrimento, acolhendo e fortalecendo essa criança por meio do autoconhecimento do adulto de hoje.

Portanto, o objetivo desse estudo de caso foi compreender o efeito da descoberta da criança interior no relacionamento conjugal.

\section{Método}

\section{Tipo de estudo}

Este é um estudo de caso realizado a partir do Curso denominado: Capacitação nas Técnicas de Resgate da Autoestima - Cuidando do Cuidador, ministrado pelo seu idealizador, Prof. Dr. Adalberto de Paula Barreto. O Curso contou com 26 participantes, entre eles dois casais. Após a vivência do resgate da criança interior, realizou-se uma entrevista semiestruturada com um dos casais. Durante a semana de curso o ministrante desenvolveu mais 09 vivências complementares de acolhimento da criança interior. A entrevista com o casal e as gravações das partilhas após cada vivência foram gravadas e transcritas. As observações sobre a participação do casal durante a semana de curso foram registradas no caderno de notas da pesquisadora e transcritas para análise.

Para o estudo de caso foi convidado o casal participante do Curso Cuidando do Cuidador, com mais de dez anos de casamento. Descrição: Casados há 21 anos, o casal possui dois filhos, um menino de 13 anos, e uma menina de 09. Ele tem 45 anos, ela, 48 anos. Ambos são servidores públicos e possuem nível superior completo.

\section{Critérios de inclusão e exclusão}

Foi entrevistado um casal inscrito no Curso Cuidando do Cuidador, que assinou o Termo de Consentimento Livre e Esclarecido. Para este estudo foi estabelecido como critério de exclusão, o casal com menos de dez anos de relacionamento. Esta pesquisa foi aprovada pelo Comitê de Ética da Plataforma Brasil pelo CEP 958272. 


\section{Local de estudo}

Este estudo foi realizado no Ceará, Brasil.

\section{Análise dos dados}

Para análise qualitativa da entrevista utilizou-se a análise do discurso (BAKHTIN, 1992; ORLANDI, 1988; ROCHA-COUTINHO, 1998). Inicialmente fez-se a leitura das entrevistas para o levantando dos principais temas. Esse processo resultou na identificação de categorias. Posteriormente, realizou-se a fragmentação, ou seja, nova análise segundo os temas elencados inicialmente, para estabelecimento da ordem de importância e a sequência dos temas encontrados. Obteve-se quatro temas centrais e um ou mais subtemas para cada categoria. $\mathrm{O}$ registro das demais gravações e anotações foi comparado ao longo da semana, para acompanhar a evolução do casal.

\section{Estudo de Caso}

\section{Chegando ao curso...}

Temal: Escolha do Curso

\section{Categoria 1.1 - Como chegaram até este curso}

[...] eu comecei a observar meu relacionamento, se eu estou vendo o problema nele, deve ser meu o problema, então vou procurar cuidar de mim. ...Ai passou algum tempo, a nossa relação estava um pouco esfriada... No aniversário de 21 anos de casamento, eu falei bem assim, "eu quero ir fazer o cuidando do cuidador, mas eu quero que você vá comigo". O que eu vim buscar mesmo aqui, é a minha essência, eu vim fazer esse curso por mim realmente, eu vim porque eu achava que era uma oportunidade de eu estar comigo. Aproveitei para trazê-lo, porque eu acho que isso vai fazer com que o nosso casamento dê assim um "up" (CECÍLIA).

Eu cai de para quedas, foi bem assim mesmo. Assim, eu não tinha expectativa nenhuma porque eu não conhecia, eu vim completamente às cegas, mas eu acho que foi bom isso (CARLOS ALBERTO).

\section{Após a vivência da criança Interior...}

Tema 2: A descoberta da influência da criança interior

\section{Categoria 2.1 - Perdão e a criança interior}

Eu acho que é um crescimento interior tão grande, fazer uma aliança com essa criança, para que ela me ajude a crescer. Porque eu acho que o melhor desse curso, é porque eu vou crescer. A partir do momento que eu peço perdão 
para essa criança e digo, venha comigo, seja feliz do meu lado, eu sou uma pessoa extremamente séria... (CECÍLIA).

\section{Categoria 2.2 - A criança interior e o futuro do relacionamento}

Então quando eu penso numa criança junto comigo, eu acho ótimo, porque eu vou até ser mais tranquila com os meus filhos, porque eu sou muito severa com eles sabe? Eu sou uma mãe carinhosa, mas eu sou severa (CECÍLIA).

Agora eu acho que vai ser uma diferença no sentido de a gente poder, assim, trabalhar essa questão, da gente poder identificar isso, e tomar uma atitude adulta, mais positiva, e não deixar que essas feridas anteriores, ressurjam assim, em momentos de conflito (CARLOS ALBERTO).

\section{Categoria 2.3 - A busca da criança interior vitoriosa}

[...] eu levo a minha vida de uma forma muito séria sabe? E eu quero essa alegria da minha criança para mim (CECÍLIA).

Tema 3: Criança interior e relacionamento conjugal

\section{Categoria 3.1 - Descoberta da criança interior}

Eu acho que essa descoberta da criança interior, tem a ver com o crescimento da autoestima, e isso vai influenciar no nosso casamento, no sentido de a gente saber separar o que é problema meu, pessoal, do que é um problema familiar, do que é um problema dela (CARLOS ALBERTO).

Eu nunca fiz nenhum trabalho antes que resgatasse essa criança interior. Eu falei: essa criança nunca vai aparecer, porque eu não me lembro de nada até os 08 anos de idade da minha vida. ..., mas ela apareceu... Então eu acho que muitas vezes a gente estava discutindo lá em casa, e eu achava que eram duas crianças discutindo. Assim, ele estava falando dos medos dele, e eu falando dos meus medos, e estava tudo misturado no meio da relação... (CECÍlIA).

\section{Categoria 3.2 - consequência da descoberta da criança interior e o casamento}

E a partir dessa perspectiva, agora, a gente já tem bagagem de conhecimento para saber discernir. Eu acho que, a gente deve estar chegando num outro nivel de relacionamento, em que a gente possa identificar antes de se começar um conflito, identificar o que realmente é um conflito, o que é herança de cada um que está sendo trazido ali, para o meio daquele conflito (CARLOS ALBERTO).

Então agora ou a gente vai juntar as crianças para brincarem juntas, ou a gente vai ser adulto em algum momento, alguém tem que tomar uma decisão, e assim, tirar mesmo esse peso das minhas costas, porque eu, acho que muitas vezes eu faço isso mesmo, eu espero que ele tome uma decisão, ele não toma, ai eu vou e tomo entendeu? (CECÍLIA). 


\section{Tema 4: Conflito conjugal e a criança interior}

\section{Categoria 4.1 - A manifestação do sofrimento da criança interior no relacionamento.}

Em alguns momentos, em discussões com ela, eu sempre achei ela muito autoritária, eu acho que nisso me manifestava aquele sentimento que eu tinha em relação à minha mãe, que a minha mãe sempre foi uma pessoa mais autoritária, aquela pessoa que comandava a casa (CARLOS ALBERTO).

Os meus irmãos se tornaram todos alcoólatras, eles não faziam nada, ficavam sentados no sofá o dia inteiro, e eu acho que eu misturo muito. É a criança daquela época que olha para ele, entendeu? Quando Carlos Alberto acorda e já vai pro computador jogar, (Não que eu ache certo levantar e ficar na frente do notebook, eu ainda acho que está errado), mas, eu identifico em mim, aquela menina que via aquela situação dos irmãos, sem fazerem nada e eu não podia fazer nada. E ficava irritada com aquilo. Então eu acho que eu implico com ele por uma situação anterior (CECÍLIA).

\section{Discussão}

O fator motivador de estudar uma díade conjugal está em que, em sua dinâmica, reside o fato de serem duas individualidades e uma conjugalidade. Na dinâmica do casal existem dois sujeitos, dois projetos de vidas não comunicados, duas expectativas, sonhos e desejos, duas identidades contendo histórias idiossincráticas herdadas de suas famílias de origem, cada um com sua "criança interior" ferida ou não, que, na relação a dois, constroem e convivem com uma conjugalidade, ou seja, um desejo conjunto, uma nova história de vida em forma de casal, constituindo-se numa identidade conjugal. Essa identidade conjugal é, metaforicamente, um caleidoscópio de emoções e padrões relacionais herdados da família de origem.

A satisfação conjugal é, sem dúvida, um conceito subjetivo, implicando em ter as próprias necessidades e desejos satisfeitos, assim como corresponder, em maior ou menor escala, ao que o outro espera, definindo um dar e receber recíproco e espontâneo (NORGREN et al., 2004).

Norgren et al. (2004) afirmam em seus estudos sobre o casamento que, um dos motivos dados pelos cônjuges para permanecem casados é por acreditarem que o casamento é parceria para a vida toda e por se sentirem responsáveis um pelo outro, bem como por haver amor. Segundo as autoras, esses motivos foram apresentados nessa ordem pelos cônjuges norteamericanos e canadenses e constaram entre os seis primeiros motivos apontados em todos os países estudados, com exceção do Chile.

A identidade conjugal está marcada pelas necessidades básicas, satisfeitas ou não satisfeitas da criança interior. A criança interior é um dos arquétipos apresentados por Jung: 
$\mathrm{O}$ arquétipo representa essencialmente um conteúdo inconsciente, o qual se modifica através de sua conscientização e percepção, assumindo matizes que variam de acordo com a consciência individual na qual se manifesta (JUNG, 2008, p. 17).

$\mathrm{O}$ arquétipo da criança interior,

É tudo o que é abandonado, exposto e ao mesmo tempo o divinamente poderoso, o começo insignificante e incerto e o fim triunfante. A "eterna criança" no homem é uma experiência indescritível, uma incongruência, uma desvantagem e uma prerrogativa divina, um imponderável que constitui um valor ou desvalor último de uma personalidade (JUNG, 2008, p. 300).

Entende-se por criança interior todos os aspectos imaturos, infantis, que fazem o sujeito sofrer desnecessariamente e em exagero, podendo levá-lo a adoecer (BOZZA, 2015, p. 128).

O Curso Cuidando do Cuidador, além de ser uma capacitação para quem deseja trabalhar com grupos, é também uma forma de terapia em grupo. Cecília (sujeito desse estudo de caso), declarou em entrevista, que pediu ao marido que lhe desse de presente, em comemoração aos seus 21 anos de casamento, a vinda do casal ao curso, pois entendia que a relação conjugal necessitava de algum movimento.

Eu comecei a observar meu relacionamento, se eu estou vendo o problema nele, deve ser meu o problema, então vou procurar cuidar de mim....Ai passou algum tempo, a nossa relação estava um pouco esfriada... No aniversário de 21 anos de casamento, eu falei bem assim, "eu quero ir fazer o cuidando do cuidador, mas eu quero que você vá comigo" (CECÍLIA).

Todas as questões de sofrimento que levam o sujeito a buscar por terapias, podem se afirmar e serem entendidas como aspectos de sua criança interior que necessitam amadurecer (BOZZA, 2015, p. 128).

O entendimento sobre o arquétipo da criança interior não é novidade entre os terapeutas psicanalistas, porém pode ser pouco utilizado ou conhecido, entre as demais abordagens terapêuticas. Embora esse olhar sobre a criança interior seja psicanalítico, este conceito é explorado no Curso Cuidando do Cuidador. Este tem em seu eixo estrutural, o pensamento sistêmico. Essas duas abordagens são complementares no resultado final do curso.

$\mathrm{Na}$ abordagem sistêmica, um casal pode ser compreendido como a menor unidade de interação social. Pensar sistemicamente é pensar no aspecto relacional do casal. Este é um subsistema familiar estruturado em forma de díade.

[...] quando se pensa sobre o casal, ainda em termos genéricos, é comum evocar-se uma ideia associada à dimensão afetiva que preserva um homem $\mathrm{e}$ uma mulher unidos. $\mathrm{O}$ compromisso entre ambos é mais ou menos duradouro, 
frequentemente com vistas à geração de filhos e à formação de nova família nuclear (MONTEIRO, 2001, p. 2).

Os autores Carter e McGoldrick (1995) destacam que a negociação desse novo vínculo conjugal marca uma mudança qualitativa no ciclo de vida das famílias de origem de cada parceiro. A existência do casal implica um nível maior de diferenciação e autonomia entre os parceiros e seus grupos familiares originários. Estabelece-se a possibilidade do início de uma nova geração.

Bowen (1978), desenvolveu o conceito de diferenciação do eu e postulava que o nível de diferenciação da família que os indivíduos adquirem é transmitido pela própria família de origem. Esse nível de diferenciação do eu da família de origem é fundamentalmente necessário para o desenvolvimento dos novos e saudáveis vínculos afetivos. Para o autor essa necessidade de diferenciação do eu da família de origem também está relacionada à necessidade do estabelecimento de alguma diferenciação, quando os indivíduos se propõem a construir e a pertencer a novos subsistemas, como por exemplo, o casamento.

A dialética do casamento pode se tornar a busca pela individuação.

Então eu acho que muitas vezes a gente estava discutindo lá em casa, e eu achava que eram duas crianças discutindo. Assim, ele estava falando dos medos dele, e eu falando dos meus medos, e estava tudo misturado no meio da relação... Essas descobertas da minha criança estão fazendo com que eu repense o meu casamento, como que eu estava nele... (CECÍLIA).

O casamento como meio de individuação deve ser um caminho pelo qual se opta, e não um dever social, pois os cônjuges elegem-se para um confronto de amor e rejeição, no qual conhecer-se a si mesmo e ao outro pode ser conhecer o bem e o mal (CARVALHO, 1999).

\section{Durante o curso...}

E a partir dessa perspectiva, agora, a gente já tem bagagem de conhecimento para saber discernir. Eu acho que, a gente deve estar chegando num outro nivel de relacionamento, em que a gente possa identificar antes de se começar um conflito, identificar o que que realmente é um conflito, o que é herança de cada um que está sendo trazido ali, para o meio daquele conflito (CARLOS ALBERTO).

Segundo Diniz-Neto (2005), existem dois eixos que aparecem na literatura, sobre os estudos dos processos da dinâmica conjugal, em relação aos processos de formação e dissolução da conjugalidade: o da satisfação/insatisfação conjugal e o da estabilidade/ instabilidade conjugal. 
Uma relação conjugal, como um composto químico, tem propriedades próprias únicas, além das características dos elementos que se fundem para formar o composto. Ela é uma entidade, nova e diferente, mas suas propriedades, embora únicas preservam uma relação dinâmica específica com os elementos que se ligaram para sua criação. Em outras palavras, os princípios psicológicos que governam o comportamento de um indivíduo e aqueles que governam o comportamento de uma relação não são os mesmos (ACKERMAN, 1986, p.156).

Braz et al. (2005), aponta que há fortes evidências dos prejuízos causados pelas disfunções familiares no desenvolvimento dos filhos, isto é, há uma correlação positiva entre os distúrbios na relação conjugal e/ou dos genitores enquanto indivíduos e os problemas de comportamento da criança.

Pensando a família e o casal sistemicamente,

O importante é sabermos que a família é uma instituição complexa que não se resume naquele núcleo pai, mãe e filho. Ela está mergulhada num caldo social e cultural e no seu próprio caldo das várias gerações familiares que a precederam, sofrendo a influência de uma série de variáveis, que vão além da sua própria organização (GROISMAN, 2013, p. 111).

Então quando eu penso numa criança junto comigo, eu acho ótimo, porque eu vou até ser mais tranquila com os meus filhos, porque eu sou muito severa com eles sabe? Eu sou uma mãe carinhosa, mas eu sou severa (CECÍLIA).

Desta forma, há evidências de que cada cônjuge, sujeito desse estudo, trouxe prejuízos emocionais de sua família de origem, que marcaram a criança interior em suas respectivas infâncias, e hoje se manifestam em forma de conflitos na relação conjugal.

Em alguns momentos, em discussões com ela, eu sempre achei ela muito autoritária, eu acho que nisso me manifestava aquele sentimento que eu tinha em relação à minha mãe, que a minha mãe sempre foi uma pessoa mais autoritária, aquela pessoa que comandava a casa. Então eu acho que em diversos momentos, eu vi a minha mãe nela, e eu acredito que eu tenha reagido de forma como se fosse aquela criança lá que tivesse de frente com a mãe, mas que hoje, a situação é diferente. Que hoje eu sou adulto, então não tinha que estar ouvindo as coisas daquela forma, daquela maneira (CARLOS ALBERTO).

O motivo da criança representa o aspecto pré-consciente da infância da alma coletiva. Dessa forma, ao esquecer na sombra as lembranças dolorosas da sua infância real, de criança carente o jovem passa a "carente de infância, perdendo suas raízes". O arquétipo da criança divina traz os opostos do velho e do porvir, trazendo a conexão com as raízes psíquicas e possibilitando a criatividade, a emergência do novo e da transformação (JUNG, 2008, p. 260285).

Segundo Pincus e Dare (1987), o casal compartilha uma organização subjetiva. Esta organização é determinante de escolhas e motivações inconscientes. Cada parceiro realiza um 
intercâmbio de sentimentos inconscientes que configura uma espécie de contrato secreto de casamento.

Esse contrato secreto poder estar ligado a uma promessa reparatória inconsciente. Segundo Benedito (1996) se, um indivíduo buscar alguém ou um cônjuge, que represente

\begin{abstract}
Uma promessa reparatória de suas vivências passadas e cindidas, configura uma projeção defensiva, ou seja, um movimento da psique em que conteúdos inconscientes permanecem presos à sombra e dificultam o desenvolvimento da personalidade. Por outro lado, se a escolha do parceiro representar um caminho para o desenvolvimento mútuo, constitui uma projeção criativa caracterizada pela tentativa de integrar aspectos inconscientes à consciência em favor do crescimento (CARVALHO, 1999, s/p).
\end{abstract}

Hillman (1971) também chama a atenção para este mundo subjetivo e aponta para a constituição arquetípica (subjetiva) que é a criança. O autor afirma que esta dimensão contribui para o adulto redescobrir a sua imaginação. Um modo de imaginação que não encara a criança como vulnerabilidade emocional e realidade imaginal, mas como uma potência imaginante capaz de revitalizar as nossas "fantasias racionalizadas". É ao mito da força redentora da criança que o homem se apega, pois, ela é o "fim triunfante".

Vale ainda, destacar que após a descoberta da criança interior, faz-se necessário ir em busca do perdão a si mesmo, aos pais e ao cônjuge.

\title{
Chegando ao fim do curso...
}

Porque eu acho que o melhor desse curso, é porque eu vou crescer. A partir do momento que eu peço perdão para essa criança e digo, venha comigo, seja feliz do meu lado... (CECÍLIA)

Com relação ao perdão familiar, é certo que todas as pessoas querem "perdoar ou ser perdoados por alguém, principalmente da nossa família, devido aos atos que foram praticados na nossa infância ou adolescência, de forma ativa ou passiva" (GROISMAN, 2013, p. 76).

Como observa Casarjian (1997) não existe relação tão importante quanto dos pais com seus filhos, sendo este relacionamento o formador do "fundamento emocional das nossas famílias" (CASARJIAN, 1997, p. 83).

Na maioria das vezes quando os pais ou avós voltam ao passado, contando suas histórias de família, ao ouvi-las, percebe-se que na maioria das vezes eram conflitos considerados 
normais, mas mal resolvidos. Muitos pais guardam para si estes conflitos, que também acabam passando para seus filhos de forma inconsciente (LIMA, 2011, p. 1).

Os caminhos do amor são aprendidos e escolhidos, e "cada pessoa traz para o relacionamento amor e os obstáculos ao amor que aprendeu" (CASARJIAN, 1997, p. 109). Em muitos relacionamentos ocorrem incidentes, dos quais um dos parceiros acaba se ferindo, ficando em seu interior ressentimentos e raiva por atos e atitudes de seu parceiro, como de causar embaraço frente aos amigos, ignorá-lo e ser infiel. "Permitir que comportamentos realmente inaceitáveis persistam causa ressentimento, culpa e comportamento disfuncional, desvitalizando o casal". Neste sentido é importante esclarecer na relação o que é aceitável e o que não é para ambos (CASARJIAN, 1997, p. 112).

Nos pensamentos de Casarjian (1997, p. 145), “perdoar a si mesmo é provavelmente o maior desafio que se irá encontrar: essencialmente, é o processo de aprender a se amar e se aceitar, não importa o que aconteça".

[...] a finalidade do autoperdão é esclarecer as ilusões. Medos e autojulgamentos que nos aprisionam no papel de nossos próprios carcereiros; é descobrir a opção de nos aposentarmos desse mister impiedoso, para que possamos estimular a verdade plena de quem e do que somos (CASARJIAN, 1997, p. 145).

Portanto, embora a manifestação da criança interior no relacionamento conjugal, questão subjetiva, somado as questões objetivas (situação econômica, trabalho, casa, cotidiano etc.), o casamento aponta um potencial inigualável de satisfação de algumas das necessidades básicas do ser humano (pertencimento, afeto, proteção, segurança, amor, cuidado). Desta forma, o casal em estudo, apesar dos conflitos, ainda mantém o desejo da conjugalidade e vislumbra novas estratégias para melhorar o relacionamento a partir da descoberta da criança interior.

\section{Implicações para Futuras Pesquisas}

Sugere-se outros estudos comparativos, ou seja, que sejam realizadas entrevistas com diversos casais e em diferentes cursos de Capacitação nas Técnicas de Resgate da Autoestima - Cuidando do Cuidador, bem como em outros trabalhos terapêuticos que resgatam e acolhem a criança interior para a produção de mais evidencias científicas. 


\section{Considerações finais}

As transformações vividas pelo casal, após o resgate e acolhimento da criança interior, puderam ser constatadas no relato e comportamento dos cônjuges, o que representa um aspecto valioso de evidência científica.

Os dados analisados não são conclusivos, porém pôde-se constatar, por meio desta metodologia científica, que o processo terapêutico ocorrido durante uma semana de curso do Cuidando do Cuidador, proporcionou a descoberta da criança interior e a consciência de sua interferência na relação conjugal.

No processo terapêutico, ocorrido durante o curso, gradativamente, o casal foi trabalhando as questões ligadas à sua criança interior, e foi ganhando mais suavidade, reestabelecendo a intimidade. A medida em que cada um tomava consciência da interferência da sua criança interior no relacionamento conjugal, aumentava o reconhecimento dos padrões disfuncionais de comportamento que precisam ser modificados. As vivências terapêuticas (movimento das forças internas) e as partilhas e o apoio em grupo (movimento das forças externas), auxiliaram o casal na busca de mais diferenciação.

À medida que cada membro da díade conjugal foi se tornando mais diferenciado ao longo da semana terapêutica, ou seja, quando começam a diferenciar as questões do casal, de suas experiências vividas nas respectivas famílias de origem, começaram a ressignificar e redimensionar essas experiências na realidade atual, buscando um caminho próprio, único, surgindo um espaço para escolhas pessoais e do casal. A autoestima de cada um amentou, e a intimidade entre eles foi naturalmente aumentando durante a semana. Cada um, dentro do próprio processo terapêutico de autoconhecimento, teve oportunidade de rever as suas histórias, dores e sofrimentos da infância e transformá-las em aceitação, perdão e força para enfrentar os desafios do casal daqui para frente.

A expectativa do esposo em relação ao curso Cuidando do cuidador foi: "Eu esperava que fosse um curso de autoajuda, com dinâmicas. Mas o que se vivencia aqui transcendeu qualquer expectativa que eu pudesse ter; por mais positiva que fosse".

Afirma ainda que a experiência em participar do curso Cuidando do Cuidador: "foi incrivel. As transformações que aconteceram em mim, me parecem ser definitivas".

A esposa participou do curso para: "aprender a conviver comigo e me capacitar a viver com o outro".

Suas necessidades iniciais foram: "A necessidade de estar comigo mesma e tirar o peso dos meus ombros". 
A esposa leva para a vida profissional e pessoal a seguinte aprendizagem desta experiência: "Resgatei minha criança interior e a levo comigo de mão dadas, ambas (ela e sua criança interior) perdoadas e amadas. Isto mudou minhas expectativas e autoconfiança".

Desta forma, entrar em contato com a criança interior aponta para o diferencial dessa experiência terapêutica, pois moveu o casal na busca de si mesmo. Proporcionou esse olhar para o Self, para o "Eu Sou", que foi fundamental para o encontro consigo mesmo, bem como para que superassem a crise e o esfriamento da relação conjugal.

Portanto, o curso TRA-Cuidando do Cuidador ofereceu um espaço de aprendizagem do autocuidado, bem como uma forma de aprender a cuidar do outro com um comportamento adulto. O resgate da criança interior e seu acolhimento ofereceu uma forma diferente de olhar a situação de conflito conjugal. Nesta semana terapêutica foi possível levantar evidências de que por meio do autoconhecimento e da consciência as manifestações da criança interior (passado) na vida presente da díade conjugal, é possível prevenir conflitos e somatizações. Isto ficou evidenciado no relato de um novo repertório de estratégias de resolução de conflitos, em vez de continuarem recorrendo aos mesmos padrões de comportamento aprendidos na família de origem.

Este casal procurou dar movimento ao relacionamento em nome do amor.

O amor é empoderamento, é autoconfiança, é fluxo. É confiar na força interior do outro. Amor é tudo que liberta e movimenta a vida de geração em geração. Possui a sutileza de manter acesa a chama interior, iluminando o caminho a ser seguido, mas nem sempre isso acontece nos relacionamentos. $\mathrm{O}$ amor que faz a mim e ao outro sofrer não é amor, é o gemido da criança ferida que carrega uma culpa, é a "sombra" que precisa ser vista (MARTINI, 2019, p. $37)$.

A “sombra” dos cônjuges foi vista. É possível seguir em frente com um amor adulto.

\section{REFERÊNCIAS}

ACKERMAN, N.W. Diagnóstico e tratamento das relações familiares. Porto alegre: Artes Médicas, 1986.

BAKHTIN, M. Estética da criação verbal. São Paulo: Martins Fontes, 1992.

BENEDITO, V. D. Y. Amor conjugal e terapia de casal: uma abordagem arquetípica. São Paulo: Summus, 1996.

BOWEN M. De la familia al individuo: la diferenciación del si mismo en el sistema familiar. Barcelona: Paidós, 1978. 
BOZZA, M. G. C. Argila: espelho da Auto expressão: um método para manifestação do inconsciente. 2. Ed. rev. e ampl. Curitiba: Ed. do autor, 2015.

BRAZ, M. P. et al. Relações Conjugais e Parentais: Uma Comparação entre Famílias de Classes Sociais Baixa e Média. Psicologia: Reflexão e Crítica, v. 18, n. 2, p. 151-161, 2005.

CARTER, B.; MCGOLDRICK, M. As mudanças no ciclo de vida familiar: uma estrutura para a terapia familiar. Porto Alegre: Artes Médicas, 1995.

CARVALHO L. A. P. P. O Jogo de Areia em terapia conjugal: uma proposta de intervenção. Universidade Presbiteriana Mackenzie. Faculdade de Psicologia. Monografia apresentada ao Programa de Iniciação Científica - Trabalho de Graduação Interdisciplinar da Faculdade de Psicologia; como parte dos requisitos para a obtenção do título de Psicólogo. São Paulo, 1999.

CASARJIAN, R. O livro do perdão: o caminho para o coração tranquilo. 6. ed. Rio de Janeiro: Rocco, 1997.

DINIZ-NETO, O. Conjugalidade: proposta de um modelo construcionista social de terapia de casal. 2005. Tese (Doutorado) - Pontifícia Universidade Católica do Rio de Janeiro, Rio de Janeiro, 2005. (não publicada)

GROISMAN, M. O Código Da família: mandamentos que devem reger as relações familiares. Rio de Janeiro: Núcleo pesquisas, 2011.

GROISMAN, M. A arte de perdoar: terapia sistêmica breve no casamento e na infidelidade. Rio de Janeiro: Núcleo Pesquisas, 2013.

HILLMAN, J. Abandoning the Child. Eranos-Jahrbuch, v. 40, p. 357-407, 1971.

JUNG, C. G. A psicologia do arquétipo da criança. In: Os arquétipos e o inconsciente coletivo. Obras Completas. vol. IX/1. 6. ed. Petrópolis: Vozes, p. 151-180, 2008.

JUNG, C. G. Símbolos da transformação. In: Obras Completas. vol. V. 6. ed. Petrópolis: Vozes, 2008.

\section{MARTINI, M. G.P. Quando o passado ainda dói-criança interior um caminho pra superar traumas e conflitos. Rio Grande do Sul: Ed. CAIFCOM, 2019.}

MONTEIRO, A. M. Avanços no estudo da conjugalidade: os casais de dupla carreira. Psicol. cienc. prof., Brasília, v. 21, n. 3, p. 10-19, set. 2001. Disponível em

http://www.scielo.br/scielo.php?script=sci_arttext\&pid=S1414-

98932001000300003\&lng=pt\&nrm=iso. Acesso em: 07 ago. 2020.

NORGREN, M. B. P. et al. Satisfação conjugal em casamentos de longa duração: uma construção possível. Estudos de Psicologia, v. 9, n. 3, p. 575-584, 2004.

ORLANDI, E. P. Discurso e leitura. São Paulo: Cortez, 1988. 
ROCHA-COUTINHO, M. L. A análise do discurso em psicologia: algumas questões, problemas e limites. In: SOUZA, L. de; FREITAS, M. F. Q. de; RODRIGUES, M. M. P. (Orgs.), Psicologia: reflexões (im)pertinentes. São Paulo: Casa do Psicólogo, 1998. p. 319348.

\section{Como referenciar este artigo}

MARTINI, M. da G. P. A criança interior e o casamento: reflexões a partir do curso cuidando do cuidador. Temas em Educ. e Saúde, Araraquara, v. 16, n. esp. 1, p. 462-476, set., 2020. eISSN 2526-3471. DOI: https://doi.org/10.26673/tes.v16iesp.1.14304

Submetido em: 20/05/2020

Revisões requeridas: $30 / 05 / 2020$

Aprovado em: 25/08/2020

Publicado em: 30/09/2020 